\title{
CRÍTICA E NORMATIVIDADE: BREVE LEITURA FILOSÓFICA-SOCIAL SOBRE A SOLIDARIEDADE POLÍTICA E O ORÇAMENTO PARTICIPATIVO
}

\author{
[CRITIQUE AND NORMATIVY: A SOCIAL-PHILOSOPHICAL INTRODUCTION TO POLITICAL \\ SOLIDARITY AND PARTICIPATORY BUDGET]
}

José Henrique Sousa Assai * Universidade Federal do Maranhão

\begin{abstract}
Resumo: A Filosofia Política encontrou-se ultimamente (mais precisamente na última década) com desafios normativos que exigem cada vez mais esforços para respondê-los, tais como: despolitização da (na) esfera pública, cosmopolitismo, soberania, direitos humanos, tolerância etc. Este artigo pretende responder ao problema da despolitização da (na) esfera pública levando em consideração um argumento social-ontológico para a pesquisa crítica no qual assume a posição de que o orçamento participativo (que é expressão política de uma forma de solidariedade) enquanto instituição participativa (entidade social) pode auxiliar no processo de repolitização da esfera pública ao se constituir na sociedade democrática enquanto medium normativo com pretensões de resolução das patologias sociais de uma comunidade social.

Palavras-chave: Esfera Pública; Orçamento Participativo; Teoria Crítica
\end{abstract}

ABstract: The Political Philosophy has encountered lately (more precisely in the last decade) with normative challenges that will increasingly require efforts in trying to respond to them such as: depoliticising of political public sphere, cosmopolitism, the national exodus by issues politi-cal- institutional-ethnic, human rights, sovereignty, tolerance etc. This article intends to answer the problem of the depoliticising of the (in the) public sphere taking into account a social-ontological argument for critical research in which it assumes the position that the participatory budget (which is the political expression of a form of solidarity) while participatory institution (social entity) can help in the process of repoliticisation of the public sphere by being constituted in the democratic society as a normative medium with pretensions of resolution of the social pathologies of a social community.

KEYwORDS: Public Sphere; Participatory Budgeting; Critical Theory

\section{Contextualizando a Pesquisa}

Ч $\mathrm{m}$ dos desafios normativos da Filosofia Política precisamente nessa década articular uma forma de (re)pensar a democracia não só enquanto uma expressão do poder do povo (populus potestatem), mas, sobretudo, na perspectiva do problema da admissibilidade temática em estabelecer paradigmas normativos inseridos em um cenário sócio-político (pós) convencional - especificamente no tocante ao processo de despolitização da esfera pública política - que balizem a democracia (do) * Professor da Universidade Federal do Maranhão). Pesquisador do Centro de Pesquisas em Democracia-CEPEDE, na Universidade Federal da Paraíba. Doutorando em Filosofia na Pontificia Universidade Federal do Rio Grande do Sul, com estágio sanduiche apoiado pela CAPES/PDSE na Europa Universität Flensburg Institut für Soziologie / European Studies, sob a orientação do prof. Dr. Hauke Brunkhorst. m@ilto:jhs.assai@ufma.br 
no Estado de Direito. Nesse sentido, novos problemas reverberam no tecido societário (ordem filogênica) a nível tanto local quanto global - como, por exemplo, despolitização da esfera pública, cosmopolitismo, o êxodo nacional por questões políticas-institucionais-étnicas, direitos humanos, soberania, tolerância, religião e esfera pública etc. - e, ao mesmo tempo, novas possibilidades de resposta engendram novos caminhos da pesquisa crítica ${ }^{1}$. O legado da Teoria Crítica ainda pode responder para tais questões e, por assim dizer, tanto a pesquisa crítica quanto à própria democracia são convidadas a se reinventarem no sentido de se autocompreenderem reflexivamente enquanto propostas de pensamento temático-filosófico e de governabilidade ${ }^{2}$. Com o intuito de apresentar uma proposta à questão da democracia como expressão do poder do povo e que, ao mesmo tempo e mais profundamente, exige ancoradouros para dar legitimidade ao exercício da força democrática, a fim de encetar uma via ao processo de politização da esfera pública-política em um cenário prenhe de patologias sociais, pretendo explicitar um elemento coparticipe da democracia (que possibilite responder ao problema central dessa pesquisa que é a questão do processo de repolitização da esfera pública) qual seja a solidariedade política que, por sua vez, é concebida no interior de uma esfera pública política autorreferente ao Estado de Direito democrático e que também se vincula ao que chamo aqui de orçamento participativo como medium normativo de um Platzhalter democrático. Como forma de explicitar tal "jogo" político-democrático e, enquanto uma linha de investigação crítica na filosofia política, proponho primeiramente considerar a ideia de esfera pública política - retomando especificamente a compreensão habermasiana presente em "Ach Europa" - como esse espaço (para o ensejo de fundamentações e inclusive de caráter normativa) que possui uma força e um telos emancipador (1.1) a fim de que, em um segundo momento, se possa vincular o espaço público-político com o princípio da solidariedade (2) enquanto procedimento não só cívico, mas, sobretudo, político e que oferece concretamente alternativas práticas para uma orientação à práxis e, por fim, tomando por referência que a solidariedade política se constitui, em nossa pesquisa, como fundamento para a ação social na efetivação do orçamento participativo, tentarei explicitar que o projeto político do referido orçamento participativo (OP) se candidata a ser um possível medium normativo na democracia (normative Platzhalter) que tem como autorreferência seu próprio povo constituindo-se, assim, como expressão objetiva na forma de governo no interior do Estado de Direito democrático no qual busca garantir e efetivar direitos (sociais, políticos, civis e econômicos) (3).

\subsection{DEMOCRACIA E ESPAÇO PÚBLICO POLÍTICO}

Quando Habermas definiu a esfera pública como assaz importante para uma concepção societária democrática, ele o fez inicialmente caracterizando-a enquanto contexto sócio-histórico até chegar aos implexos normativo-institucionais presentes na sociedade $^{3}$. Assim, ao caracterizar a esfera pública (Öffentlichkeit) como elemento fundamental na urdidura teórica de sua concepção de sociedade, Habermas toma por consideração que uma determinada forma democrática exige também uma esfera pública (política) capaz de não só fazer eco aos anseios do povo (Politische Öffentlichkeit verbreitet ein babylonisches Stimmengewirr $)^{4}$, - sendo um sistema de comunicação intermediário entre as organizações e a sociedade civil - mas, sobretudo, em acolhendo tais ecos (que na linguagem honnethiana seriam também as patologias sociais) possam tomá-los sob um ponto crítico-normativo e inclúi-los numa agenda programática emancipatória (práxis) de uma sociedade 5 . 
No tocante a definição de esfera pública em "Ach Europa” o "11 Escrito Político" já parte, por um lado, do pressuposto da diferença conceitual entre "sociedade e sociedade civil"; e, por outro, de "esfera pública e esfera pública política". Essa diferenciação é decisiva para a presente pesquisa, pois ao tratar da última parte dessa abordagem haverá, como pressuposto, essa diferenciação nocional antes assinalada. Tal diferenciação a que me refiro traduz, no tocante a abordagem habermasiana, uma modalidade de releitura conceitual e estrutural tanto da esfera pública quanto da sociedade sendo que esse último é elemento estruturante da ideia de mundo da vida (Lebenswelt). Não poderei me ater nesses pormenores aqui, mas trago à baila essa questão - e apresento minimamente logo a seguir uma curta explicitação desses conceitos - em virtude da relevância dos mesmos em uma pesquisa que se tome por orientação o legado habermasiano.

Apenas para fins explicitativos e de forma brevíssima, o conceito de sociedade em Habermas decorre precisamente em "Theorie des Kommunikativen Handelns" (TKH) onde tacitamente ele define a sociedade como "os ordenamentos legítimos que regulam aos participantes da comunicação sua pertença aos grupos sociais e, com isso, asseguram a solidariedade" 6 . Essa compreensão habermasiana acerca da sociedade foi retomada nos mesmos contornos nocionais em "Vorstudien und Ergänzungen zur Theorie des Kommunikativen Handelns"7 e já em "Fakzität und Geltung" (FG) houve uma glosa ao conceito. Dessa feita, fora inserido o termo "civil" para a ideia de sociedade sugerindo ao leitor que a noção seminal do conceito de sociedade ficou mais próxima de uma abordagem normativa (nesse caso a aproximação da esfera pública com o aparato institucional da sociedade civil): "a sociedade civil compõe-se de movimentos, organizações e associações, os quais captam os ecos dos problemas sociais que ressoam nas esferas privadas, condensam-nos e os transmitem, a seguir, para a esfera pública política" ${ }^{8}$. Já a ideia de esfera pública é descrita como "um fenômeno social elementar do mesmo modo que a ação, o ator, o grupo ou a coletividade [...] a esfera pública não pode ser entendida como uma instituição, nem como uma organização, pois ela não constitui uma estrutura normativa capaz de diferenciar entre competências e papéis [...]. A esfera pública pode ser descrita como uma rede adequada para comunicação de conteúdos, tomadas de posição e opiniões [...]"9; mas, em "Ach Europa" Habermas acrescenta à esfera pública o termo "política". Não é só mais uma glosa em seu repertório conceitual acerca da esfera pública, porém, tal acréscimo atesta, sobretudo, um vínculo ainda que tácito com a normatividade. Por esfera pública política Habermas a definiu como "por um lado, sistema de comunicação intermediário entre as orientações (deliberações) organizadas formalmente e as negociações; por outro, os eventos e as conversações informais no âmbito da sociedade civil do sistema político" ${ }^{\prime 10}$.

Só que para Habermas permanece clara a tarefa constitutiva da esfera pública política em ser um medium que filtra e controla tudo aquilo que é produzido pela comunicação política"1; entretanto, Habermas se dá conta que a "Politische Öffentlichkeit" necessita, por um ponto de vista racional, da legitimidade no próprio processo democrático. Para isso, ela há de sustentar e orientar pontos de vista normativos (normativen Gesichtspunkten) e é nesse aspecto que o modelo deliberativo de democracia "entra em cena" 12 ; no entanto, ainda na compreensão habermasiana presente em "Zur Vernunft der Öffentlichkeit", para que tal normatividade se efetive é preciso que a sociedade civil traduza algumas referências empíricas capazes de aglutinarem os discursos (na perspectiva da ação comunicativa) assim como as decisões legiferantes da esfera civil. Só que ainda nesse texto Habermas remete-se, sob o ponto de vista das evidências empíricas (empirische Evidenzen) ao quadro categorial da 
comunicação política e mais especificamente na gênese estatal do sistema político como exemplo conceitual da esfera pública que no seu entendimento já se faz presente tanto no sistema político quanto na sociedade civil ${ }^{13}$. Essa dual articulação traduz, por assim dizer, as categorias basilares da teoria da sociedade habermasiana (mundo da vida e sistema) e que também nos permitem pensar que, mais notadamente em "Ach Europa", por um lado, são transpostas para a dual relação entre centro e periferia (Zentrum und Peripherie) e, por outro, resultam das opiniões públicas refletidas enquanto produto da esfera pública política: "[...] as opiniões públicas refletidas resultam do círculo comunicativo entre Centro e Periferia - enquanto produto da esfera pública" 14 . Sob o aspecto de uma "politische Öffentlichkeit" Habermas alude às evidências empíricas sob uma perspectiva modal - ainda considerando os Inputs e Outputs - da (na) esfera pública política; porém, não as submete a uma posição que se constitua como "Hintergrund" e/ou à práxis. Parece que a relação estabelecida entre as categorias internas e subjacentes a arena da comunicação política não se perfazem enquanto medium para uma normatividade que, em sua compreensão mais estrita no interior de uma Teoria Crítica, deveria orientar para um telos de emancipação. O modelo deliberativo, nesse caso, apresentado por Habermas parece funcionar dentro de um esquema formal-categorial de uma esfera pública política compreendida no interior do conceito de poder comunicativo estando circunscrita a sua teoria da ação comunicativa e que poderia, por assim dizer, comprometer uma proposta de pensamento à práxis. Parece que Habermas se dá conta disso e entende que o poder não se autocompreende apenas como comunicativo dentro de um quadro de maior referência teórica de cunho político. Nesse sentido, ele apresenta uma quaternária cratologia de sua compreensão estrutural de poder subjacente a esfera pública-política, mas ainda envolta ao conceito de comunicação, a saber: poder político, poder social, poder econômico e poder mediático ${ }^{15}$. Devemos nos ater a essa tipologia cratológica já que parecem reconduzir à concepção de esfera pública política um quantum emancipatório e não apenas formaltipológico: poder político (diz respeito ao processo de legitimação e justificação do Estado Constitucional democrático que se orienta basicamente pelos processos de decisão políticas); poder social (trata da ordem estatal de uma sociedade estratificada); poder econômico (baseia-se nas formas de poder do sistema capitalista); poder da mídia (que se apoia na tecnologia e na infraestrutura da comunicação de massa) ${ }^{16}$.

Habermas, no entanto, tende a reconhecer que, sob o ponto de vista da comunicação política, ainda há dificuldades para a participação da sociedade civil no processo de formação da opinião pública e da vontade (política) ${ }^{17}$. Ele chamou de participação autônoma (autonomie Beteilung) ${ }^{18}$ esse processo de desacoplamento da sociedade civil perante as formas de poder existentes na sociedade e isso gera também àquilo que ele definiu como as patologias da comunicação política (Pathologien der politischen Kommunikation). Tais problemas (patologias na linguagem habermasiana e mais ainda honnethiana) ocorrem principalmente em virtude da relação descontínua entre o processo de institucionalização (assim como sua estrutura funcional) na sociedade (mediática principalmente) e as expectativas normativas oriundas do modelo deliberativo. Nesse caso, parece que Habermas ainda se dá conta tanto do problema da esfera institucional como medium normativo ${ }^{19}$ quanto da questão sobre a esfera pública política seja autocompreendida apenas na abordagem pragmático-semântica e comunicativa, mas não propriamente normativa (no sentido de se conceber a instituição social como medium à emancipação).

O problema quanto ao déficit institucional na esfera pública política também arguido pelo professor Lubenow ainda continua sem uma plausível resposta por parte de Habermas. Há, sem dúvida, na concepção habermasiana, um enfraquecimento da 
esfera institucional como telos (normativo) para a emancipação. Ela também deveria estar orientada para a perspectiva normativa e não somente encapsulada no arranjo teórico do agir comunicativo galvanizado pela pragmática formal e semântica linguística.

Sobre esse potencial déficit institucional a respeito da concepção social habermasiana parece que o processo de participação na formação da opinião política (Beteiligung an der politischen Meinungsbildung) torna-se decisivo numa análise que leve em conta a colonização da esfera pública. Tal questão repousa na tratativa de autocompreensão do processo solapador na qual sofre a esfera pública política.

Em “Ach Europa” Habermas permanece fiel ao diagnóstico de que o imperativo sistêmico-econômico se constitui como uma forma de paralisia da sociedade civil e isso gera uma específica colonização da esfera pública (Kolonisierung der Öffentlichkeit) ${ }^{20}$. Por outro lado, as expectativas normativas (normativen Erwartungen) são continuamente latentes e eclodem na sociedade civil fazendo parecer, por assim dizer, que apenas ficar circunscrito ao modelo comunicativo não permite postular que tais "normativen Erwartungen" sejam colocadas a um patamar de resolução de problemas (Problemlösung) onde, mediante a formação da opinião pública e da vontade política dos cidadãos (politische Meinungs- und Willensbildung der Bürger), se possa conceber uma esfera pública política dotada de orientação normativa ${ }^{21}$, isto é, uma tentativa diferenciada do que principalmente em "Fakzität und Geltung" onde Habermas tenta aproximar a esfera pública política aos processos institucionais de caráter normativo. Como uma primeira tentativa de resposta institucional-normativa ao processo de despolitização da esfera pública política, penso que a compreensão crítico-reconstrutiva de solidariedade política de Hauke Brunkhorst, ancorado em pressupostos de uma Teoria Crítica, possa prestar sua colaboração ${ }^{22}$.

\title{
2 SOLIDARIEDADE COMO POTENCIALIDADE NORMATIVA À PRÁXIS SOCIAL
}

\author{
Solidarität ist solide. Solidus meint eine Verpflichtung fürs Ganze, \\ die Gesamthaftung, die Gesamtschuld, die Solidar-obligation: obligation \\ in solidum
}

Hauke Brunkhorst

$\mathrm{Na}$ perspectiva de uma pesquisa crítica $^{23}$ assume-se aqui a recepção habermasiana de uma compreensão racional orientada pela destranscendentalização ${ }^{24}$ cujo fundamento se assenta na vinculação do pensar e do agir para com os contextos sócio-históricos ${ }^{25}$. É com base nesse pressuposto que remeto a ideia de uma solidariedade normativa cujo fundamento filosófico se constrói a partir da ideia de uma razão destranscendentalizada e que, por sua vez, tematiza o sujeito socializado em seus múltiplos contextos num mundo objetivo ${ }^{26}$. Tal empreendimento decorre na admissibilidade de uma razão destranscendentalizada que se constitui enquanto um "Einbettung der vergesellschafteten Subjekte" e que, por esse modo, uma vez que o sujeito (agentes sociais) se autocompreenda enquanto copartícipe de um ordenamento social e político repleto de contradições se inicia o processo de participação dos interesses em comum numa tentativa de resolver tais contradições. É com esse ato de participar ativamente na esfera pública é que parto da ideia de que o agir solidário de cunho político se constitui como um medium normativo que retoma àquelas normative Erwartungen (expectativas normativas) e as assume como uma orientação à práxis mediante canais institucionais que devem articular tal procedimento. A seguir, retomo o 
conceito de solidariedade em Brunkhorst que, a meu ver, tem em si os elementos fundamentais concernentes a essa pesquisa: solidariedade enquanto autoconstitutivo medium normativo orientada pelos processos institucionais.

No seu livro intitulado Solidarität ${ }^{27}$, Brunkhorst apresenta os três níveis (Stufen der Solidarität) daquilo que ele entende por solidariedade. Em sua definição conceitual, Brun-khorst estabelece uma hierarquia tipológica da solidariedade que inicia com a "amizade civil" passando pela dimensão metafísico-teológica de cunho judaico-cristão até chegar aos Direitos Humanos a partir de 1789. Não nos interessa aqui cada um desses elementos pormenorizadamente, porém temos que nos orientar "indo direto ao ponto" sobre o que ele compreende por solidariedade e o que nessa compreensão se vincula com um entendimento normativo que engendra formas de ação social emancipatórias.

É no prefácio de Solidarität que Brunkhorst apresenta o seu conceito de solidariedade: "as conquistas sociais do bem comum" 28 e essas conquistas estão associadas à ideia dos bens fundamentais (Grundgüter) e dos bens públicos (Öffentliche Güter $)^{29}$ que, se efetivadas mediante a conquista da práxis político-social, traduzem-se por meio do cânone de procedimentos normativos pela aquisição ao direito de existência social (soziale Existenzrecht $)^{30}$. Pelo que me parece essa ideia do "soziale Existenzrecht" presume uma forma jurídica para que seja efetivada tomando em consideração o medium institucional; ou haveria outra forma de realizar o direito de existência social sem a mediação institucional participativa no interior da democracia deliberativa? De outro modo, se Brunkhorst fala sobre conquistas isso significa dizer que ele evoca, numa leitura crítico-dialética, a gênese constitutiva da Teoria Crítica qual seja a identificação dos problemas de um determinado contexto social e, ao mesmo tempo, a procura pelo seu potencial resolutivo (Problemlösung). Assim, ao tentar resolver as questões cruciais de uma determinada sociedade estabelece-se, por assim dizer, uma busca a um espaço para novas fundamentações (Raum der Gründe) ${ }^{31}$ e essa conquista não vem de forma gratuita sem qualquer forma de contraposição, de luta; pelo contrário, ela vem acompanhada de uma pujança e afã normativos ${ }^{32}$ que, sob as formas procedimentais da democracia deliberativa e participativa, faz emergir pela busca por mediações resolutivas e, dentre as quais, assumir a posição de procurar também as mediações de caráter institucional - que eu tratarei tematicamente na última parte desse artigo e que é conhecida por orçamento público-participativo - para a tratativa desses mesmos problemas. Assumir tal procedimento de busca resolutiva dos problemas sociais mediante os canais institucionais resulta, por primeiro, considerar como efetiva a concepção destranscendenalizada de razão enquanto "Verkörperung der Vernunft" na qual está "sensível" às contingências patológicas da sociedade; e, em segundo lugar, em outro sentido, ao retomar um conceito destranscendental de razão, remete por parte dos agentes sociais inseridos em seus contextos históricos, na perspectiva de um argumento social-ontológico, uma postura política de depositar nos canais institucionais o mínimo de confiança possível (Institutionenvertrauen) ${ }^{33}$. É bem verdade que nesse ponto a solidariedade não está só vinculada as questões formais das instituições sociais, mas mediante a práxis das instituições, que visam a emancipação, o agir solidário ganha não só na sua efetivação prática, mas também em sua maneira formal-procedimental o exercício social para sua efetivação.

Mais uma vez, sob o olhar da filosofia, a razão destranscendentalizada se desloca para o processo de incorporação à práxis social. Ela se despe de sua forma mais "sublime" - qual seja a transcendental - e toma a forma "profana" de um determinado soziale Lebenswelt. Ela - a razão corporificada - se revela, nesse sentido, dialeticamente como luta pelas conquistas políticas, sociais e econômicas de uma 
sociedade despojada desses mesmos bens mais gerais e necessários para os mais desprovidos ao direito de existência social, por exemplo. Nesse processo de desacoplamento destranscendental a razão se corporifica assumindo formas sócioorganizacionais ${ }^{34}$ de luta pela práxis. O "seu lado solidário" emerge como contraponto normativo (alter ego) ao seu lado idealista, metafísico, transcendental. Agir, nesse caso, é agir socialmente e essa ação solidária se caracteriza como sendo, por que não dizer, um Platzhalter de uma Teoria Crítica revisitada (no sentido de entender a razão como corporificada e "sensível" às contingências históricas).

De forma reiterada, uma vez que o agir solidário se constitua em um Platzhalter de uma concepção normativa crítica, a razão ${ }^{35}$ se desloca para um processo de destranscendentalização - já que a ela se despe de seu lado puramente transcendentalmetafísico - e nessa reorientação destranscendentalizadora da razão a ação solidária assume um papel importante, pois se caracteriza como um modo de tentar encontrar soluções para os problemas encontrados (patologias sociais) no interior da práxis social (contingências históricas). É nesse sentido que eu associo às patologias da razão ${ }^{36}$ essa fixidez em se considerar a razão enquanto apenas transcendental e não levar em conta o "outro lado": que ela está também vinculada a processos e configurações geopolíticas e históricas que engendram as sociedades (a tese da corporificação da razão); mas, por outro lado, é por isso também que Brunkhorst fala a respeito dos processos de dessocialização do indivíduo e a proletarização da sociedade ${ }^{37}$ como problemas cruciais das sociedades modernas e aí é que entra em cena a solidariedade normativa enquanto possibilidade de ação social mediante uma concepção crítico-normativa ${ }^{38}$. O agir solidário enquanto Platzhalter crítico e normativo de uma Teoria Crítica exige um espaço de atuação e esse locus é basicamente a esfera pública. O entendimento de Brunkhorst sobre esfera pública possui uma conotação dinâmica e esse elemento que dá dinamicidade baseia-se, numa leitura habermasiana, na força comunicativa (aqui Brunkhorst aproxima-se de Habermas) baseadas no engajamento e na abertura (para assuntos e debates que visem à resolução de conflitos) como critérios de legitimação da esfera pública. $\mathrm{O}$ engajamento, nesse caso, significa que se partindo do agente racionalcomunicativo, e depois da ação social articulada coletivamente, há a crescente efetivação de mecanismos decisórios (participativo-democrático) para e na construção social. A partir do engajamento e da abertura enquanto disposições (ações) sociais que se efetivam na esfera pública o agir social e a solidariedade se fundem e se orientam para a práxis constituindo-se, por assim dizer, nesse Platzhalter democrático.

Se, por um lado, para Brunkhorst, "a institucionalização deve ser vista como o medium da liberdade perante o conflito" 39 - e dessa forma devemos "estar atentos" para com o perigo do institucionalismo radical que pode, a seu tempo, solapar em seu próprio nome o engajamento solidário normativo, pois, nessa perspectiva, o quadro institucional estaria acima do "sujeito racional e coletivo" - ; por outro, para a efetividade do agir solidário não menos importante é a força sócio-normativa da esfera pública política sem olvidar obviamente dos canais institucionais ${ }^{40}$ que se constituem como mediações normativas e procedimentais para a emancipação. Como explicitação desses pressupostos, penso que as premissas de Von Detel sejam pertinentes naquilo que "está em jogo" ao se afirmar a imbricada relação entre agir solidário político e os canais institucionais e que, prima facie, já antecipa a última parte deste artigo uma vez que pensar as instituições enquanto medium normativo é, por assim dizer, também vinculá-las a um argumento filosófico do tipo ontológico-social. Nesse sentido, Detel formula cinco argumentos de uma ontologia social (sozialontologisches Argument) ${ }^{41}$ :

a) as instituições são um conjunto de sanções com base num conjunto de regras; 
(b) as instituições são erigidas e mantidas na existência por pessoas oriundas do exercício do poder regulativo para seguir as regras; (c) que a orientação por regras (mencionadas no item b) é uma ação coletiva; (d) que o exercício do poder regulativo mencionado (item b) é igualmente um agir (ação) coletivo (a); (e) que as pessoas participantes do exercício do poder e do seguimento das regras consideram a validade do conjunto de regras como condição necessária para a manutenção do sistema social em que elas vivem e que elas mantêm essa manutenção para o bem ${ }^{42}$.

Detel está convencido da força vinculativa da existência das instituições com o agir que se dá coletivamente e, portanto, que ocorre na esfera social. A ideia básica é que as instituições não sejam vistas como algo separado da natureza humana e que, em virtude da necessidade da vida em sociedade, elas deveriam fazer parte da agenda sócio-política de uma comunidade civil; mas, ao contrário, que as instituições passem a ser vistas enquanto elemento constitutivo do seu próprio agir (social), pois esse tipo de ação socialmente realizada é determinado pelas obrigações (deveres) e por autorizações (Berechtigungen) que formam o escopo de uma comunidade jurídica (Rechtsgemeinschaft). Só que uma comunidade, em seu sentido mais amplo, se autocompreende enquanto coparticipação de seus agentes sociais se houver àquilo que Detel chama de verbreitete Hintergrundüberzeugungen ${ }^{43}$ (difundida convicção de contextos básicos) no sentido que somente em virtude do reconhecimento de pertença a um determinado grupo é que se inicia o processo social que forma a comunidade o que significa reconhecer também que toda comunidade - assim como a esfera pública ${ }^{44}$ não está imune àquilo que Forst chamou de Rechtsfertigungsherausforderungen (desafios de justificação) ${ }^{45}$. É nesse processo tanto de autocompreensão do agir social baseado na força subjetiva e intersubjetiva quanto no reconhecimento (Anerkennung) no intuito de que a comunidade política possa efetivar meios para solucionar os tais Rechtsfertigungsherausforderungen mediante os canais institucionais que reitero o conceito de solidariedade enquanto ação política e não apenas cívica. É com esse entendimento que a solidariedade política se insere enquanto como potencial normativo da (para a) ação social, pois ela permite - utilizando-se também e de forma muito particular da mediação institucional (dimensão sócio-ontológica) - que o processo destranscendentalizador da razão se efetive no sentido de que tanto a inserção do sujeito (ora puramente transcendental e pela destranscendentalização passa a ser compreendido como sujeito social) nos múltiplos contextos de mundos da vida (lebensweltliche Kontexte) quanto o cruzamento da cognição com o falar e o agir (Verschränkung der Kognition mit Sprechen und Handeln) tornam-se não só possíveis, mas, sobretudo, realizáveis ${ }^{46}$ na perspectiva de um argumento social ontológico para a pesquisa crítica. Isso não significa afirmar que a tensão inerente a destranscendentalização do sujeito (verdade e justificação racional) esteja superada ${ }^{47}$, mas essa é outra questão.

No que diz respeito à relação entre os cinco fundamentos ontológicos para se pensar as instituições e a potencialidade normativa do agir social da solidariedade política é preciso que tomemos por consideração dois fatores que os explicito a seguir e que, por sua vez, os mesmos se relacionam com uma forma de pesquisa crítica que apresento a seguir:

A existência de entidades sociais e com isso a sociedade devem ser constituídas através de disposições intencionais coletivas e ações coletivas; sujeitos humanos não estão apenas na posse dos meios de produção, mas, sobretudo, também de posse dos meios para a Transformação [...] da realidade social ${ }^{48}$. 
Os dois argumentos acima descritos vinculam-se a um dos aspectos mais fundamentais de uma pesquisa crítica que é justamente a crítica a(s) ideologia(s) no sentido de uma crítica as contradições $^{49}$, pois uma vez que o caráter destranscendentalizante da razão se efetive por meio do agir social solidário na qual conflua o ordenamento político com o normativo as diversas concepções ideológicas ideologia enquanto sistemas de convicção que possuem consequências práticas ${ }^{50}$ passam a ser vistas não apenas como puro obstáculo para a emancipação, porém, de forma muito particular, como um canal mediático (medium normativo) para a construção efetiva da sociedade mais equilibrada ${ }^{51}$. A solidariedade política enquanto elemento de uma pesquisa crítica também se situa na esfera dessa IdeologieKritik por entender que tanto as práticas sociais quanto as instituições fazem parte daquilo que Jaeggi chama de demonstração da variabilidade (Aufweis der Veränderbarkeit) ${ }^{52}$, pois no interior delas emergem, sob o ponto de vista da facticidade, os problemas e suas potencialidades de resolução e, sendo assim, a própria crítica a ideologia passa a se constituir como um tipo de "normatividade de segunda ordem" já que por meio dela pode ser possível a emancipação. Nesse cenário, a razão destranscendental se vincula a crítica imanente da pesquisa crítica $^{53}$ e, por assim dizer, ao se despir de sua aura transcendental, a razão é lançada aos múltiplos contextos de mundo da vida; portanto, ao se colocar como forma copartícipe de um determinado mundo da vida o agir solidário passa a se comprometer com a busca pelas soluções dos problemas sociais (Auf-lösung der Paradoxie) ${ }^{54}$ e, por isso mesmo, ele se coloca como uma forma de ação social detentora de pretensões de normatividade retomando, por assim dizer, a gênese constitutiva da pesquisa crítica, qual seja, o interesse emancipatório ${ }^{55}$.

No intuito de expor de que maneira essa coparticipação público-política é possível na urdidura social em contextos de Estados Democráticos de Direito, delinearei, a seguir, a ideia fundamental do orçamento participativo pensado a partir de uma filosofia social que leva a sério os potenciais emancipatórios existentes na sociedade. $\mathrm{O}$ orçamento participativo candidata-se como essa potencialidade de constituição (mediação) normativa, pois essa modalidade política-deliberativa, a meu ver, sob um ponto de vista de uma filosofia social e política de cunho crítico-reflexivo, possui um medium normativo e constitutivo de um Platzhalter democrático justamente por se fundamentar, em sua arquitetônica principiológica, como uma esfera institucional orientada para a práxis auxiliando, dessa forma, o entendimento e tomada de posição sobre as deficiências nas condições sociais da autorrealização do sujeito e da sociedade ${ }^{56}$.

\section{OrÇamento Participativo (OP): Releitura CRítica e nORMATIVIDAde}

Sem me ater aos contextos históricos mais detalhados da gênese constitutiva do orçamento participativo quer sejam tanto de caráter local quanto de cunho mais amplo ${ }^{57}$ esse modelo de gestão e administração pública ganhou notoriedade no Brasil nos idos de 1980 até o início da década de 1990 e com a mesma força que emergiu enquanto proposta participativo-democrática também feneceu antes da virada do século. Não pretendo esmiuçar o cenário sociológico do solapamento desse projeto social, porém é de bom alvitre lembrar que o Orçamento participativo (OP) adquiriu diversos matizes ou formas de existir, em sua conceptualização tanto formal quanto procedimental, e mesmo possuindo uma caracterização de princípios básicos ${ }^{58}$.

Anterior à questão procedimental o que remete a presente pesquisa é, sob uma perspectiva de uma Filosofia Social e Política, a explicitação do caráter normativo do 
OP vinculado a uma forma procedimental-deliberativa de concepção de Estado de Direito democrático. Em síntese: até que ponto pode-se tomar a sério a ideia básica de que o OP possa se constituir em um medium normativo que se proponha a responder ao problema central dessa pesquisa, qual seja: a repolitização da (na) esfera pública política num cenário atual envolto de dificuldades normativas por estar inserido, dentre tantos aspectos, em um contexto pós-convencional e pós- metafísico? Proponho como resposta ao problema da repolitização na esfera pública o uso de um argumento socialontológico para a pesquisa crítica que, nesse caso, é traduzida pela mediação institucional para a efetivação dessa forma patológica da razão (despolitização da esfera pública). Como critério metodológico eu explicitarei de uma breve caracterização empírica e sociológica do que ocorreu no Brasil na formação histórica e social do OP (3.1) vinculada a uma pesquisa crítica que leva em conta justamente um argumento social-ontológico ${ }^{59}$ cuja fundamentação se localiza na instituição social enquanto medium à práxis e à emancipação (na linguagem honnethiana "resolução das patologias sociais") (3.2).

(3.1) Os movimentos sociais populares, desde os anos de 1970 no Brasil e durante todo o período militar, tentaram se consolidar como agentes sociais autônomos e com capacidade de articulação e, mediante distintas formas de participação. Nesse período tentou se buscar no Brasil o (re)vigoramento dos direitos civis, políticos e sociais de cidadania "perdidos" no auge do militarismo. Ainda mais decisivo, sob o ponto de referência empírico-social, foi o pleito de 1988 e de 1989 porque, com o resultado das urnas daquela eleição, a favor do então presidente Fernando Collor de Mello houve um processo de solapamento da tentativa de expandir os direitos sociais além dos direitos materiais de cidadania. Esse era o cenário de uma época em que notadamente a esfera pública política foi abalada em seus fundamentos pelo processo brutal de despolitização. Uma alternativa encontrada naquela época como resposta para esse processo despolitizador da e na esfera pública política foi o orçamento públicoparticipativo (como expressão de uma forma de cidadania local que pretendeu responder a falta de legitimidade do governo no curso desse período supracitado) no intuito de efetivar àqueles direitos (civis, políticos e de cidadania) ${ }^{60}$ perdidos durante $\mathrm{o}$ período militar e também ofuscados pelos pleitos de 1989 e 1990. A participação descentralizada - já que a centralização radical é modus operandi inerente de uma política que não se preocupa efetivamente com a plena realização dos direitos dos cidadãos - e a cogestão (o Executivo divide com o povo parte da responsabilidade decisória mediante acordos formais e, na maior parte, não consagrados em leis) pública passaram a se constituir, portanto, em um mote normativo, obviamente carregado de pretensões normativas, para a construção e efetivação de direitos ${ }^{61}$. Nesse sentido, tanto a cidadania (constituição de uma rede interacional entre grupos e atores sociais) assim como a legitimidade ${ }^{62}$ política (aceitação e apoio das iniciativas e das ações do governo) passaram a ser vistas como pressupostos vinculativos da ação do orçamento participativo.

A ideia da cidadania fundamenta-se, sob o ponto de vista local e de acordo com o modelo brasileiro; ela começa com o bairro de um município e oportuniza a todos os interessados no processo de emancipação (resolução das patologias sociais) a real possibilidade de construir coletivamente esse espaço de debate e tomadas de posição (deliberação). Por motivos de delimitação temática não me atenho aqui aos aspectos mais particulares (procedimentais e sociológicos) do orçamento público-participativo, porém compreendo que esse espaço para o debate e para a deliberação (onde pretensões de validade são acareadas discursivamente) pode ser entendido, naquilo que se conhece pela Teoria Crítica do Raum der Gründe (espaço de fundamentações) ou 
mesmo ainda como um Problemlösungsprozess ${ }^{63}$, pelo orçamento participativo. Esse espaço das (para) fundamentações permite pensar o OP enquanto um processo de solução de problemas orientado tanto normativa quanto emancipatoriamente.

(3.2) O orçamento participativo provê sob o ponto de vista de uma pesquisa filosófica-política que as expectativas normativas (normative Erwartungen) não fiquem apenas nas expectativas, porém que a força emancipatória (emanzipatorische kraft) já presente em seus princípios (A), características fundamentais (B), funcionamento (C), critérios distributivos e técnicos (D), natureza (E) sejam eficazes para a efetivação dos direitos básicos (sociais, econômicos, civis, políticos):

(A) participação aberta a todos os cidadãos sem nenhum status especial atribuído a qualquer organização inclusive as comunitárias;

- combinação da democracia direta e representativa cuja dinâmica institucional concede aos próprios participantes a definição das regras internas;

- alocação dos recursos para investimentos baseada na combinação de critérios gerais e técnicos;

(B) ter como base geográfica uma divisão territorial da cidade;

- ter conselhos regionais deliberativos;

- todos os moradores da área de abrangência do Conselho fazem parte do mesmo e o elegem, tendo este que prestar contas de seus atos periodicamente;

- permitir modificações na sua esfera de competência, a qual deve aumentar à medida que os conselhos se fortalecem;

- os Conselhos respeitarão a autonomia operacional da administração municipal;

- deve ser resguardado o princípio de fidelidade do representante ao representado;

- as diversas entidades da sociedade civil atuarão no sentido de reforçar a participação nas assembleias regionais [...];

(C) quando as decisões dependerem de uma decisão da Câmara caberá aos Conselhos exercer sua pressão organizada;

- definição do setor do governo no qual será desenvolvido o OP;

- descrição do ciclo do OP: reunião inicial para apresentação, reuniões regionais para seleção de prioridades, reuniões intermediárias para a confirmação das escolhas, negociação entre Executivo e representantes da população sobre a montagem da proposta orçamentária;

- encaminhamento da proposta para a Câmara Municipal;

- prestação de contas públicas;

- comissões de fiscalização e acompanhamento de obras;

(D) critérios técnicos: demográficos, de carência territorial dos bens e dos 
serviços públicos e de preferência popular;

- critérios baseados na deliberação pública;

- critériOs de exequibilidade;

(E) decisão e soberania popular materializada na noção de deliberação pública;

- decisão sobre o conjunto do orçamento da prefeitura;

- prestação de contas e transparência para a efetivação do controle social das decisões ${ }^{64}$.

Tais postulados (de A até E) do OP tendem a possibilitar a efetivação das expectativas normativas da sociedade transformando-as em uma práxis emancipatória. Aqui, tanto os bens fundamentais (Grundgüter) quanto os bens públicos (Öffentliche Güter) se fundem num único programa social e político visando à efetivação dos direitos de existência social (soziale Existenzrecht) que fora salientado por Brunkhorst. Sendo assim, retomando a noção tanto de Detel quanto de Titus Stahl sobre o fundamento ontológico das instituições sociais, creio que a ideia básica de um argumento social-ontológico (sozialontologisches Argument) com vestígios de uma normatividade crítica é revisitada em sua expressão mais fundamental: a constituição de instituições sociais com orientação à emancipação. $\mathrm{O} O \mathrm{OP}$, ao seu tempo, tentou constituir para a sociedade esse Platzhalter de uma democracia de caráter deliberativo muito embora as contingências históricas a tenham afastado da agenda programática dos governos desde então. Quando menciono as contingências históricas remeto mais notadamente ao momento específico da redemocratização e o desafio do rearranjo institucional (pressuposto social-ontológico como é o caso do OP concebido enquanto instituição participativa ${ }^{65}$ que possui um telos emancipador) tanto naquele período e muito mais no momento presêntico em que passamos na sociedade brasileira de forma mais particular ${ }^{66}$.

Quanto ao uso de uma abordagem ontológica-social para a pesquisa crítica que tente responder à questão central dessa pesquisa que é o problema da repolitização da esfera pública, creio que subjaz aqui outro problema na qual se deve enfrentar: sob a perspectiva normativa, há existência imanente de normas ${ }^{67}$ Retomo aqui algumas considerações de Stahl no tocante a essa pergunta que se reporta a questão de uma ontologia social para a pesquisa na Teoria Crítica.

Em “Immanente Kritik”, Titus Stahl apresenta em três grandes partes desse seu livro a imbricada relação entre crítica imanente e ontologia social. A explicitação de Stahl, a meu ver, busca primeiramente: responder à questão na qual Honneth não respondeu ${ }^{68}$, pois quando o atual Diretor do IfS (Institut für Sozialforschung) afirma que a realidade como corporificação da razão (ou razão destranscendentalizada do viés habermasiano) pode ser apresentada por um "sozialontologisches Argument", ele não o explicita no decurso de "Leiden an Unbestimmtheit"; ou seja, Honneth não explica "o como" uma abordagem ontológica-social pode ser fonte de tradutibilidade de uma realidade enquanto expressão de uma razão "destituída de sua metafísica transcendental"; e, em segundo, creio que Stahl procura uma forma de pesquisa que preencha o espaço sublinhado por Forst ${ }^{69}$ no tocante à compreensão fundamental de uma Teoria Crítica (uma Teoria Crítica enquanto “ortlos”). De outro modo: se partimos do entendimento prévio e básico de que não há um objeto "canônico" para a pesquisa crítica, então ela se autocompreende como um "espaço livre" para as mais variadas e 
multiformes maneiras de se fazer pesquisa crítica desde que a mesma seja "crítica". Nesse sentido, Stahl compreende a teoria crítica em um aspecto específico (crítica social) e dessa crítica social está inclusa a crítica imanente. Por crítica social, Stahl entende por atividade que consiste na avaliação de práticas sociais utilizando algum tipo de padrão normativo com o intento de convencer os agentes sociais que as deficiências de suas práticas (de acordo com o padrão em questão) constituem uma razão (um fundamento, motivo) para que eles mudem suas práticas e que elas se tornem melhores. Já a crítica imanente é uma forma da crítica social que avalia as práticas sociais constitutivas dos agentes sociais. Por isso que a questão fundamental de uma justificação social-ontológica da crítica imanente recai na pergunta: em que sentido existe os potenciais normativos na realidade social?

A proposta básica de Titus Stahl é a de que se a questão fundamental sobre uma teoria da crítica imanente seja identificada como problema para a existência imanente de normas disto se segue para a aceitabilidade e justificação dos conteúdos das normas imanentes. Stahl utiliza uma tipologia da crítica social para melhor explicitar seu entendimento sobre o que é crítica: Gesellschaftskritik im weiten Sinne (crítica social no sentido amplo) e Gesellschafts-kritik im engeren Sinne (crítica social no sentido estreito) e é "no sentido amplo" que reside à tentativa de melhoramento das práticas sociais e institucionais. Por isso que, ao se falar numa crítica da sociedade, Stahl argumenta que se deve primeiro perguntar sobre o significado de um padrão normativo "existente" nas práticas sociais e, nesse caso, a questão da existência remete, por sua vez, para a própria existência de uma entidade social (a questão da ontologia social pelo fato de que as premissas que exprimem os conteúdos normativos imanentes de uma comunidade social pressupõem entidades sociais). Com base nessa argumentação de Stahl, os pressupostos sociais-ontológicos de uma crítica imanente são: atitude normativa compartilhada (onde os membros de uma comunidade social partilham suas crenças, convicções, normas etc. não de uma forma puramente idiossincrática, porém na busca de uma autocompreensão social dos membros dessa mesma comunidade; reside ainda, entretanto, a questão de como fundamentar as disposições/atitudes individuais com as obrigações específicas objetivamente dadas pelas normas) e o conteúdo normativo das práticas sociais ${ }^{70}$ (como as normas práticas "estão disponíveis" numa comunidade social?). Esses dois pressupostos sociais-ontológicos vinculam-se aos conteúdos principiológicos do orçamento participativo principalmente se levarmos em conta os dados de "A" até "E" (no item II da presente sessão) como elementos de integração normativa do OP, pois essa referida proposta de participação política, enquanto instituição participativa ${ }^{71}$ (ou entidade social), tematiza tanto as posições compartilhadas ou não compartilhadas de uma determinada comunidade social quando pressupõe a participação dos munícipes do bairro na construção de uma realidade melhor quanto também prevê a acareação dos conteúdos normativos das práticas sociais ao "reportar" para o Executivo local as pretensões do melhoramento das condições sociais oriundas das reivindicações dos munícipes do bairro. Nesse sentido, o OP expressa em sua concepção originária o vínculo entre as normas imanentes e as práticas sociais quando, sob o ponto de vista da pesquisa crítico-normativa, toma a sério as condições objetivas de uma determinada comunidade social ao mesmo tempo em que reforça a ideia da real efetividade para a conquista do melhoramento das condições sociais e econômicas, por exemplo) ${ }^{72}$.

$\mathrm{O}$ orçamento participativo - enquanto entidade social-normativa - retomaria a ideia básica de Brunkhorst sobre a questão da instituição como medium para a liberdade e essa compreensão seria dada a partir da legitimação da própria procedimentalização e deliberação do orçamento público-participativo 
(Institutionenvertrauen). Confiar nas instituições não reside apenas em uma concepção institucionalista-fisiologista, mas, sobretudo, em pensá-las justamente como essa mediação normativa capaz de propor a repolitização de uma esfera pública aviltada, na linguagem habermasiana, pelos ditames do sistema. A tarefa de repolitização da esfera pública política (tomando a sério os contextos mais aviltantes do bairro primeiramente para que daí se siga as reivindicações até o Executivo local) não é um repto que tem seu capítulo finalizado com a proposta social e política do orçamento público-participativo; ao contrário, é desafio constante de um pensar crítico-normativo. Até o próprio termo/conceito de orçamento público-participativo poderia e pode ser alterado, porém no que insisto é na fundamentação filosófica e política dessa proposta que, nascida no Brasil, ganhou força normativa em muitos países e que em cada região do Brasil teve seus próprios contornos programáticos juntamente com os limites procedimentais derivados de cada experiência histórica.

Retomando: para essa pesquisa a tarefa imanente de uma Teoria Crítica (immanente Kritik) ${ }^{73}$ é constantemente atualizada na intuição basilar do orçamento participativo que se encontra inserido numa perspectiva de uma crítica interna, pois, parte, por um lado, das normas e das situações sociais existentes e, por outro, das próprias contradições internas de uma determinada realidade que se autocompreende enquanto copartícipe do Estado de Direito democrático mediante as normas constituídas (konstituierenden Normen) e a realidade institucional (institutionelle Realität) ${ }^{74}$. O orçamento participativo não deve estar imune a tais circunstâncias uma vez que ao se candidatar na urdidura social como potencialidade normativa e de emancipação está inserido não só no próprio contexto de um Estado de Direito democrático, mas, sobretudo, corresponsável de toda a construção democrática (principalmente na efetivação dos direitos políticos, sociais, civis e econômicos) inerente a ele. Para o OP permanece, portanto, o fito de levantar a pretensão de preencher o "vácuo" proposto por uma pesquisa crítica que se autocompreende enquanto ortlos e, como corolário dessa pretensão, tentar responder de alguma forma à pergunta primaz dessa pesquisa: como repolitizar a esfera pública? Creio que o OP fornece um "repertório" políticoinstitucional como alternativa responsal dessa questão. Talvez seja o caso de aprofundar ainda mais na esteira de uma filosofia social essa possibilidade normativa.

\section{REFERÊNCIAS}

ASSAI, José Henrique. De "Leiden an Unbestimmtheit" à "Erfolg an Bestimmtheit": um caminho possível da reconstrução normativa honnethiana? Revista Griot, n.1, p.226-244, 2015.

ASSAI, José, BAVARESCO, Agemir, JOZIVAN, Francisco (org.). Estudos de Filosofia Social e Política: Justiça e Reconhecimento. Porto Alegre: Editora Fi, 2015. 387 p.

ASSAI, José Henrique Sousa. Solidariedade como pressuposto de uma ontologia social: investigação possível para uma Teoria Crítica? p. 153 - 189. In: Estudos de Filosofia Social e Política: Justiça e Reconhecimento. Porto Alegre: Editora Fi, 2015, 387 p. . A ontologia social "fraca" em Habermas: o déficit normativo do mundo da vida (Lebenswelt). Revista Intuitio, n. 1, p. 215 - 225, 2014.

. A Fundamentação discursiva da teoria política em Jürgen Habermas: uma abordagem empírico-normativa do Estado. Imperatriz: Ética, 2008. 160 p.

AVRITZER, Leonardo. Civil Society, Participatory Institutions and Representation: From Authorization to the Legitimacy of Action. Dados - Revista de Ciências Sociais, Rio de Janeiro, n. 3, v. 50, p. $443-464,2008$.

BAVARESCO, Agemir, PEREIRA, Gustavo, VILLANOVA, Marcelo (org.). Justiça, Democracia e Política. Porto Alegre: EDIPUCRS, 2012. 262 p. 
BAYERTZ, Kurt. Solidarity. London: Kluwer Academic Publishers, 1999. 350 p.

BODE, Ingo. Die Organisation der Solidarität: Normative Interessenorganisationen der französischen Linken als Auslaufmodell mit Zukunft. Opladen: Westdeutscher Verlag, 1997. $366 \mathrm{p}$.

BRUNKHORST, Hauke. Critical Theory of Legal Revolutions: Evolutionary perspectives. New York: Bloomsbury Publishing, 2014a. 472 p.

. Das doppelte Gesicht Europas: Zwischen Kapitalismus und Demokratie. Berlin: Surhkamp Verlag, 2014b. 216 p.

. Solidarität: Von der Bürgerfreundschaft zur globalen Rechstgenossenschaft. Frankfurt am Main: Suhrkamp Verlag, 2002. 246 p.

DEPENHEUER, Otto. Öffentlichkeit und Vertraulichkeit: Theorie und Praxis der politischen kommunikation. Wiesbaden: Westdeutscher Verlag, 2001. 198 p.

DETEL, Von Wolfang. Grundkurs Philosophie: Philosophie des Sozialen. Stuttgart: Reclam, 2013. $191 \mathrm{p}$.

FIALA, Andrew. The Bloomsbury Companion to Political Philosophy. New York: Blooms-bury Publishing Plc., 2015. $271 \mathrm{p}$.

FLICKINGER, Hans Georg. Em nome da Liberdade: elementos da crítica ao liberalismo contemporâneo. Porto Alegre: EDIPUCRS, 2003. 176 p.

FORST, Rainer. Normativität und Macht: Zur Analyse sozialer Rechtfertigungsordnung. Berlin: Suhrkamp Verlag, 2015. 254 p.

. Das Recht auf Rechtfertigung: Elemente einer konstruktivistischen Theorie der Gerechtigkeit. Frankfurt am Main: Suhrkamp Verlag, 2007.

. Kontexte der Gerechtigkeit: Politische Philosophie jenseits von Liberalismus und Kommunitarismus. Frankfurt am Main: Suhrkamp Verlag, 1996.

FORST, Rainer, HARTMANN, Martin, JAEGGI, Rahel (org.). Sozialphilosophie und Kritik. Frankfurt am Main: Suhrkamp Verlag, 2009. 743 p.

HABERMAS, Jürgen. Ach Europa: Kleine Politische Schriften XI. Frankfurt am Mai: Suhrkamp Verlag, 2008. $191 \mathrm{p}$.

. Kommunikatives Handeln und detranszendentalisierte Vernunft. Stuttgart: Reclam, 2001. $87 \mathrm{p}$.

. Direito e Democracia: entre facticidade e validade. Tradução Flávio Beno Siebeneichler.

Rio de Janeiro: Tempo Brasileiro, 1997. 354 p. v. 2.

. Theorie des Kommunikativen Handelns: Zur Kritik der funktionalistischen Vernunft. Frankfurt am Main: Suhrkamp Verlag, 1995. 640 p.

. Fakzität und Geltung: Beiträge zur Diskurstheorie des Rechts und des demokratischen Rechtsstaats. 4. ed. ampl. Frankfurt am Main: Surhkamp Verlag, 1994. 704 p. v.2.

HÄBERLE, Peter. Hermenêutica Constitucional: A sociedade aberta dos intérpretes da Constituição: Contribuição para a interpretação pluralista e "procedimental" da Constituição. reimpr. Tradução Gilmar Mendes. Porto Alegre: Sérgio Fabris Editor, 2002. $55 \mathrm{p}$.

HERZBERG, Carsten, RÖCKE, Anja, SINTOMER, Yves. Von Porto Alegre nach Europa. Möglichkeiten und Grenzen des Bürgerhaushalts. Potsdam: Potsdam Universität, 2006.

HONNETH, Axel. Die Idee des Sozialismus: Versuch einer Aktualisierung. Berlin: Suhrkamp Verlag, 2015. $167 \mathrm{p}$.

Sofrimento de Indeterminação: Uma reatualização da Filosofia do direito de Hegel. Tradução Rurion Soares Melo. São Paulo: Esfera Pública, Singular, 2007. 145 p.

. Pathologien der Vernunft: Geschichte und Gegenwart der Kritische Theorie. Frankfurt am Main: Suhrkamp Verlag, 2007. 239 p.

. Leiden an Unbestimmtheit: Eine Reaktualisierung der Hegelschen Rechtsphilosophie. Stuttgart: Reclam, 2001. 127 p.

HORKHEIMER, Max. Traditionelle und kritische Theorie. Berlin: Fischer Taschenbuch, 2013. $304 \mathrm{p}$.

III ENCONTRO INTERNACIONAL PARTICIPAÇÃO, DEMOCRACIA E POLÍTICAS PÚBLICAS, 2017, Vitória (ES). Seminário Temático Efetividade das instituições participativas, 2017. 
JAEGGI, Rahel, LOICK, Daniel (org.). Nach Marx: Philosophie, Kritik, Praxis. Berlin: Suhrkamp Verlag, 2014. 518 p.

JAEGGI, Rahel. Alienation. Tradução Frederick Neuhouser. Columbia: Columbia University Press, 2014. $274 \mathrm{p}$.

JAEGGI, Rahel, WESCHE, Tilo. Was ist Kritik? Frankfurt am Main: Suhrkamp Verlag, 2013. $375 \mathrm{p}$.

LUBENOW, Jorge. O que há de político na Teoria da Ação Comunicativa? Sobre o déficit de institucionalização em Jürgen Habermas. Revista Philósophos 18, n.1, p. 157 - 190, 2013. . Esfera Pública e Democracia Deliberativa em Habermas: modelo teórico e discursos práticos. Revista kriterion 121, p.227 - 258, 2010. . A Categoria de Esfera Pública em Jürgen Habermas. 2007. 257 f. Tese (Doutorado em Filosofia) - Campinas, Universidade Estadual de Campinas, 2007

NETO, Nilo. Orçamento Participativo: o processo de implementação em São Luís. 2009. 156f (Dissertação). Mestrado em Políticas Públicas. Universidade Federal do Maranhão, São Luís, 2009.

NOBRE, Marcos. 1988 +30. Novos Estudos CEBRAP, São Paulo, v 35, p. 135 - 149, jul. 2016.

PETTIT, Phillip, ROBERT Goodin, POGGE, Thomas. A Companion to Contemporary Political Philosophy. Oxford: Blackwell, 2007. 891 p.

SÁNCHEZ, Félix. Orçamento Participativo: teoria e prática. São Paulo: Cortez, 2002. (Coleção Polêmicas da nossa época 97)

SANTOS, Maria Rosimary. Democracia, Orçamento Participativo e Educação Política. Revista ORG e DEMO, Unesp 7, n. 2, p.153 - 182, 2006.

SANTOS, Boaventura de Sousa. Democratizar a democracia: os caminhos da democracia participativa. Rio de Janeiro: Civilização Brasileira, 2002.

SOBOTTKA, Emil. Organizações Civis: buscando uma definição para além de ONG's e "terceiro setor. Civitas: Revista de Ciências Sociais 2, n. 1, p. 81 - 95, 2002.

. Orçamento Participativo: conciliando direitos sociais de cidadania e legitimidade do governo. Civitas: Revista de Ciências Sociais 4, n. 1, p. 95 - 109, 2004.

SCHMITT, Richard. An Introduction to Social and Political Philosophy: a question-based approach. Maryland: Rowman \& Littlefield Publishers, 2009.

SCHWAN, Gesine. Weil Europa sich ändern muss: Im Gespräch mit Hauke Brunkhorst. Frankfurt: Springer Fachmedien, 2015. 118 p.

STAHL, Titus. Immanente Kritik: Elemente einer Theorie sozialer Praktiken. Frankfurt: Campus Verlag, 2013. $475 \mathrm{p}$

TRANOW, Ulf. Das Konzept der Solidarität: Handlungstheoretische Fundierung eines soziologischen Schlüsselbegriffs. Wiesbaden: Springer Verlag, 2012. 262 p.

WARREN, Ilse Scherer. Redes de movimentos sociais na América latina - caminhos para uma política emancipatória? Caderno CRH 21, n.54, p. 505 - 517, 2008.

WESSER, Ulrich. Heterenomien des Sozialen: Sozialontologie zwischen Sozialphilosophie und Soziologie. 1. ed. Wiesbaden: Springer Fachmedien, 2011. 354 p.

WINTER, Rainer, ZIMA, Peter (org.). Kritische Theorie heute. Bielefeld: Transcript Verlag, 2007. 319 p.

\section{NoTAS}

1 FIALA, Andrew. The Bloomsbury Companion to Political Philosophy. New York: Bloomsbury Publishing Plc., 2015. $271 \mathrm{p}$.

2 BRUNKHORST, Hauke. Critical Theory of Legal Revolutions: Evolutionary perspectives. New York: Bloomsbury Publishing, 2014. 472 p.

3 HABERMAS, Jürgen. Theorie des Kommunikativen Handelns: Zur Kritik der funktionalistischen Vernunft. Frankfurt am Main: Suhrkamp Verlag, 1995. 640 p. . Fakzität und Geltung: Beiträge zur Diskurstheorie des Rechts und des demokratischen Rechtsstaats. 4. ed. ampl. Frankfurt am Main: Surhkamp Verlag, 1994. 704 p. 
LUBENOW, Jorge. A Categoria de Esfera Pública em Jürgen Habermas. 2007. 257 f. Tese (Doutorado em Filosofia) - Campinas, Universidade Estadual de Campinas, 2007.

. Esfera Pública e Democracia Deliberativa em Habermas: modelo teórico e discursos práticos. Revista kriterion, Belo Horizonte, n. 121, p. 227 - 258, jun. 2010.

- O que há de político na Teoria da Ação Comunicativa? Sobre o déficit de institucionalização em Jürgen Habermas, Revista Philósophos, Goiânia,v.18, n.1, p.157 190, 2013.

4 HABERMAS, Jürgen. Zur Vernunft der Öffentlichkeit. p. 131 - 191. In: Ach Europa: Kleine Politische Schriften XI. Frankfurt am Main: Suhrkamp Verlag, 2008. 191p.

5 STAHL, Titus. Ideologiekritik als Kritik sozialer Praktiken. p. 228 - 254. In: LOICK, Daniel, JAEGGI, Rahel (org.). Nach Marx: Philosophie, Kritik, Praxis. 2. ed. Berlin: Suhrkamp Verlag, 2014. 518p .

6 HABERMAS, Jürgen. Das Konzept der Lebenswelt und der hermeneutische Idealismus der verstehenden Soziologie. p. 182 - 228. In: Theorie des Kommunikativen Handelns: Zur Kritik der funktionalis-tischen Vernunft. 1. ed. Frankfurt am Main: Suhrkamp Verlag, 1995a. 640 p.

7 HABERMAS, Jürgen. Erläuterungen zum Begriff des Kommunikativen Handelns. p. 571 606. In: Vorstudien und Ergänzungen zur Theorie des Kommunikativen Handelns. 1. ed. Frankfurt am Main: Suhrkamp Verlag, 1995b. 606 p.

8 HABERMAS, Jürgen. O conceito "sociedade civil", p. 99. In: Direito e Democracia: entre facticidade e validade. Tradução Flávio Beno Siebeneichler. Rio de Janeiro: Tempo Brasileiro, 1997. 354 p. v. 2.

9 HABERMAS, Jürgen. O papel da sociedade civil e da esfera pública política. p. 92. In: Direito e Democracia: entre facticidade e validade. Tradução Flávio Beno Siebeneichler. Rio de Janeiro: Tempo Brasileiro, 1997. 354 p. v. 2.

10 HABERMAS, Jürgen. Die Struktur der Massnkommunikation und die Ausbildung reflektierter öffentlicher Meinungen. p. 164. In: Frankfurt am Main: Suhrkamp Verlag, 2008. 191 p.

11 Id. Ibid., p. 164.

12 "[...] Aus diesen kommunikativen Kreislauf zwischen Zentrum und Peripherie sollen - als Eigenprodukte der Öffentlichkeit - reflektierte öffentliche Meinungen hervorgehen” cf. Id.Ibid., p.167.

13 Id.Ibid., p.165.

14 Id.Ibid., p.167.

15 Habermas não abandona a sua tese fundamental da ação comunicativa e, nesse caso, estabelece sua compreensão política baseada em contornos comunicativos. Com o subtítulo "Die Machtstrukturen der Öffentlichkeit und die Dynamik der Massenkommunikation" em "Ach Europa" Habermas rearticula as categorias de poder sob uma base da sua teoria do agir comunicativo. Cf. Jürgen Habermas, 2008, p. 173 191.

16 HABERMAS, 2008, p. $173-179$.

17 HABERMAS, 1994, p. $396-397$.

18 Id.Ibid., p.178.

19 LUBENOW, 2013, p. 157 - 190.

20 HABERMAS, 2008, p. 184.

21 ASSAI, José. De "Leiden an Unbestimmtheit" à "Erfolg an Bestimmtheit": um caminho possivel da reconstrução normativa honnethiana?, Revista Griot, n.1, p. 226-244, 2015. . Solidariedade como pressuposto de uma ontologia social: investigação possível para uma Teoria Crítica?, In: DE LIMA, Francisco, ASSAI, José, BAVARESCO, Agemir, Estudos de Filosofia Social e Política: Justiça e Reconhecimento. Porto Alegre: Editora Fi, 2015. p. $153-189$.

. A ontologia social "fraca" em Habermas: o déficit normativo do mundo da vida (Lebenswelt), Revista Intuitio, n. 1, p. 215 - 225, 2014.

22 BRUNKHORST, Hauke. Solidarität: Von der Bürgerfreundschaft zur globalen Rechstgenossenschaft. Frankfurt am Main: Suhrkamp Verlag, 2002. 246 p. 
LOICK, Daniel, JAEGGI, Rahel (org.). Nach Marx: Philosophie, Kritik, Praxis. Berlin: Suhrkamp Verlag, 2014. 528 p.

JAEGGI, Rahel, WESCHE, Tilo (org.). Was ist Kritik? Frankfurt am Main: Suhrkamp Verlag, 2013. 375 p.

HONNETH, Axel. Die Idee des Sozialismus: Versuch einer Aktualisierung. Berlin: Suhrkamp Verlag, 2015. $167 \mathrm{p}$.

23 A Teoria Crítica se abre, numa perspectiva multidisciplinar e transdisciplinar, para novos horizontes e desafios em sua contínua atualização. Nesse sentido, o livro organizado por Rahel Jaeggi, Rainer Forst dentre outros, torna-se uma obra importante nesse cenário de releitura da Teoria Crítica enquanto teoria crítico-normativa sem uma forma específica de se fazer pesquisa crítica (orlos). Rainer Forst, Martin Hartmann, Rahel Jaggi et.al (org.). Sozialphilosophie und Kritik. Frankfurt am Main: Suhrkamp Verlag, 2009. 743 p.

24 HABERMAS, Jürgen. Kommunikatives Handeln und detranszendentalisierte Vernunft. Stuttgart: Reclam, 2001.87 p.

25 HABERMAS, 2001, $87 \mathrm{p}$.

26 HABERMAS, 2001,p.17.

27 BRUNKHORST, 2002, 246 p.

28 BRUNKHORST, 2002, p.7.

29 Id.Ibid.,p.110-114.

30 Id. Ibid., p.114.

31 Considerar aqui a contribuição de Rainer Forst ao tratar dos modelos deliberativos da democracia. O poder democrático, para Forst, se radica no provimento de espaços que viabilizem aos atores sociais reivindicarem suas fundamentações, argumentos etc em vista do bem comum. Cf. FORST, Rainer. Die Herrschaft der Rechtfertigung. In:

Das Recht auf Rechtfertigung: Elemente einer konstruktivistischen Theorie der Gerechtigkeit. Frankfurt am Main: Suhrkamp Verlag, 2007. p. 248 - 269.

32 DEPENHEUER, Otto. Öffentlichkeit und Vertraulichkeit: Theorie und Praxis der politischen kommunikation. Wiesbaden: Westdeutscher Verlag, 2001. 198 p.

33 SCHWAN, Gesine. Weil Europa sich ändern muss: Im Gespräch mit Hauke Brunkhorst. Frankfurt: Springer Fachmedien, 2015. 118 p. Para Brunkhorst, a institucionalização deve ser vista como o medium da liberdade, ou seja, o elemento normativo que busca repolitizar a esfera pública política. A aposta nesse caso não é ficar restrito a mecanismos institucionais como se fossem apenas instrumentais "terapêuticos" do repertório do sistema socioeconômico; mas, sobretudo, como mediação normativa que tem em seu "dever-ser" a tarefa de repolitizar a esfera pública política que se faz presente na sociedade e essa, por sua vez, é atingida por situações e cenários nem sempre benéficos a si (penso aqui, por exemplo, nas patologias sociais dos centros não só urbanos, mas especificamente rurais do nosso rincão brasileiro).

TRANOW, Ulf. Das Konzept der Solidarität: Handlungstheoretische Fundierung eines soziologischen Schlüsselbegriffs. Wiesbaden: Springer Verlag, 2012. 262 p.

34 BODE, Ingo. Die Organisation der Solidarität: Normative Interessenorganisationen der französischen Linken als Auslaufmodell mit Zukunft. Opladen: Westdeutscher Verlag, 1997. $366 \mathrm{p}$.

BAYERTZ, Kurt. Solidarity. London: Kluwer Academic Publishers, 1999. 350 p.

35 Retomo o conceito básico de razão sob um ponto de vista crítico em se estabelecer como "a capacidade de se orientar por fundamentos e justificações". Cf. FORST, Rainer. Normativität und Macht: Zur Analyse sozialer Rechtfertigungsordnung. Berlin: Suhrkamp Verlag, 2015. 254 p.

36 HONNETH, Axel. Pathologien der Vernunft: Geschichte und Gegenwart der Kritische Theorie. Frankfurt am Main: Suhrkamp Verlag, 2007. 239 p.

37 BRUNKHORST, 2002, 246 p. Paralelamente a esses dois processos supracitados pode-se também entendê-los como processos de desontogenização (indivíduo) e desfilogenização (sociedade). Tais processos estão circunscritos na teoria da sociedade de Habermas e fazem parte, por assim dizer, dos elementos constitutivos de sua concepção normativa de esfera pública (política). Cf. ASSAI, José. A Fundamentação discursiva da teoria política 
em Jürgen Habermas: uma abordagem empírico-normativa do Estado. Imperatriz: Ética, 2008. 160 p.

38 TRANOW, 2012, p. $35-92$.

39 BRUNKHORST, 2002, p. 199.

40 DETEL, Von Wolfang. Grundkurs Philosophie: Philosophie des Sozialen. Stuttgart: Reclam, 2013. p. $39-102$.

41 HONNETH, Axel. Leiden an Unbestimmtheit: Eine Reaktualisierung der Hegelschen Rechtsphilosophie. Stuttgart: Reclam, 2001. 127 p. Na versão brasileira: HONNETH, Axel. Sofrimento de Indeterminação: Uma reatualização da Filosofia do direito de Hegel. Tradução Rúrion Soares Melo. São Paulo: Esfera Pública, Singular, 2007. 145 p.

42 Detel aponta cinco fundamentos ontológicos das instituições sociais: "(a) Institutionen sind Mengen von sanktionsgestürtzten Regelmengen R;(b) Institutionen warden erzeugt und in der Existenz gehalten indem Menschen durch regulative Machtausübung dazu gebrachte warden, den Regeln R zu folgen;(c) Das in (b) erwähnte Regelfolgen ist eine kollektive Handlung;(d) Die in (b) erwähnte regulative Machtausübung ist ebenfalls eine kollektive Handlung;(e) Die an der Machtausübung und dem Regelfolgen beteiligen Menschen betrachten die Geltung der Regelmenge R. als notwendige Bedingung für die Aufrechterhaltung des gesellschaflichen System in dem sie leben und sie haben diese Aufrechterhaltung für gut." DETEL, 2013, p. 95.

43 DETEL, 2013, p. $96-97$.

44 JESTAEDT, Matthias. Zwischen Öffentlichkeit und Vertraulichkeit: Der Staat der offenen Gesellschaft: Was darf er verbergen?. In: DEPENHEUER, Otto (org.). Öffentlichkeit und Vertraulichkeit: Theorie und Praxis der politischen kommunikation. Wiesbaden: Westdeutscher Verlag, 2001. p. 67 - 110.

45 FORST, Rainer. Der Grund der Kritik: Zum Begriff der Menschenwürde in sozialen Rechtsfertigungs-ordnungen. In: JAEGGI, Rahel, WESCHE, Tilo. Was ist Kritik? Frankfurt am Main: Suhrkamp Verlag, 2013. p.150 - 164.

46 HABERMAS, 2001, p. 16.

47 Ib.Ibid., p. 22.

48 "Die Existenz sozialer Entitäten und damit die Gesellschaft, wird konstituiert durch kollektive intentionale Einstellungen und kollektive Handlungen; Menschliche Subjekte sind nicht nur im Besitz von Produktionsmitteln sondern prinzipiell auch im Besitz der Mittel zur Transformation [...] der sozialen Realität". Cf. DETEL, 2013, p. 100. Von Detel apresentaa esses dois critérios sócio-ontológicos utilizando-se de uma particularidade: quando ele cita o segundo argumento justamente no trecho entre colchetes, ele usa outro termo para dar ênfase ao processo de transformação social (Umformung). Esse termo também significa transformação, mas parece se fazer entender, para um contexto de pesquisa crítica, no sentido de que há realmente um pressuposto tanto genésico quanto marxiano para o conceito de transformação. Cf. BITTNER, Rüdiger. Kritik und wie es besser wäre. In: JAEGGI, Rahel, WESCHE Tilo. Was ist Kritik? Frankfurt am Main: Suhrkamp Verlag, 2013. p.134 - 149.

HORKHEIMER, Max. Traditionelle und kritische Theorie. Berlin: Fischer Taschenbuch, 2013. $304 \mathrm{p}$.

49 JAEGGI, 2013, p. $266-295$.

50 Id.Ibid., p. 268.

51 FORST, Rainer. Kontexte der Gerechtigkeit: Politische Philosophie jenseits von Liberalismus und Kommu-nitarismus. Frankfurt am Main: Suhrkamp Verlag, 1996.

52 JAEGGI, 2013, p. 281.

53 Id.Ibid., p. $286-288$.

54 Id.Ibid., p. $283-284$.

55 FORST, Rainer. Normativität und Macht: Zur Analyse sozialer Rechtfertigungsordnungen. Berlin: Suhrkamp Verlag, 2015. 254 p.

56 JAEGGI, Rahel. Alienation. Tradução Frederick Neuhouser. Columbia: Columbia University Press, 2014. 274 p.

57 NETO, Nilo. Orçamento Participativo: o processo de implementação em São Luís. 2009. 156 
f (Dissertação). Mestrado em Políticas Públicas. Universidade Federal do Maranhão, São Luís, 2009.

WARREN, Ilse Scherer. Redes de movimentos sociais na América latina - caminhos para uma politica emancipatória?, Caderno CRH 21, n.54, p. 505 - 517, 2008.

SANTOS, Maria. Democracia, Orçamento Participativo e Educação Política, Revista ORG e DEMO, Unesp 7, n. 2, p. 153 - 182, 2006.

SANTOS, Boaventura de Sousa. Democratizar a democracia: os caminhos da democracia participativa. Rio de Janeiro: Civilização Brasileira, 2002.

SOBOTTKA, Emil. Organizações Civis: buscando uma definição para além de ONG's e o “terceiro setor". Civitas: Revista de Ciências Sociais, n. 1, p. 81 - 95, 2002.

SOBOTTKA, Emil. Orçamento Participativo: conciliando direitos sociais de cidadania e legitimidade do governo. Civitas: Revista de Ciências Sociais, n. 1, p. 95 - 109, 2004.

PETTIT, Phillip Pettit, GOODIN, Robert, POGGE, Thomas. A Companion to Contemporary Political Philosophy. Oxford: Blackwell, 2007. 891 p.

58 HERZBERG, Carsten, RÖCKE, Anja, SINTOMER, Yves. Von Porto Alegre nach Europa. Möglichkeiten und Grenzen des Bürgerhaushalts. Potsdam: Potsdam Universität, 2006.

59 Uma interessante pesquisa a respeito da vinculação entre argumento social-ontológico e Teoria Crítica é do prof. Titus Stahl. Cf. STAHL, Titus. Immanente Kritik: Elemente einer Theorie sozialer Praktiken. Frankfurt: Campus Verlag, 2013. 475 p.

60 REIS, Helena. Direitos sociais e políticos: supostos da justiça nas democracias. In: BAVARESCO, Agemir, PEREIRA, Gustavo, VILLANOVA, Marcelo (org.). Justiça, Democracia e Política. Porto Alegre: EDIPUCRS, 2012. 262 p.

$61 \mathrm{O}$ argumento basilar de que o Orçamento participativo foi, em sua origem, uma tentativa de resposta ao processo de despolitização da esfera pública política dá-se pelo fato de que as promessas do Estado moderno para a realização efetiva dos direitos sociais, por exemplo, encontram limites desde o seu nascimento. Assim, um Estado de Direito sempre encontraria dificuldades reais (autorrealização do sujeito) em garantir a materialidade de direitos de cidadania. Cf. FLICKINGER, Hans Georg. Em nome da Liberdade: elementos da crítica ao liberalismo contemporâneo. Porto Alegre: EDIPUCRS, 2003. 176 p.

62 HÄBERLE, Peter. Reflexões sobre a Teoria da Democracia como Legitimação. In:

Hermenêutica Constitucional: A sociedade aberta dos intérpretes da Constituição: Contribuição para a interpretação pluralista e "procedimental" da Constituição. reimpr. Tradução Gilmar Mendes. Porto Alegre: Sérgio Fabris Editor, 2002. 55 p.

63 JAEGGI, 2013, p. 289.

64 SÁNCHEZ, Félix. Orçamento Participativo: teoria e prática. São Paulo: Cortez, 2002. (Coleção Polêmicas da nossa época 97)

65 AVRITZER, Leonardo. Civil Society, Participatory Institutions and Representation: From Authorization to the Legitimacy of Action. Dados - Revista de Ciências Sociais, Rio de Janeiro, n. 3, v. 50, p. $443-464,2008$.

66 NOBRE, Marcos. 1988 +30. Novos Estudos CEBRAP, São Paulo, v 35, p. 135 - 149, jul. 2016.

67 STAHL, 2013, p. 123.

68 HONNETH, Axel. Leiden an Unbestimmtheit. Stuttgart: Reclam, 2001. 127 p.

69 FORST, 2009, 743 p.

70 STAHL, 2013, p. 189 - 255. Cf. WESSER, Ulrich. Heterenomien des Sozialen: Sozialontologie zwischen Sozialphilosophie und Soziologie. 1. ed. Wiesbaden: Springer Fachmedien, 2011.354 p.

71 III ENCONTRO INTERNACIONAL PARTICIPAÇÃO, DEMOCRACIA E POLÍTICAS PÚBLICAS, 2017, Vitória (ES). Seminário Temático Efetividade das instituições participativas, 2017.

72 DETEL, Wolfang. Habermas und die Methodologie Kritischer Theorien. In: WINTER, Rainer, ZIMA, Peter (org.). Kritische Theorie heute. Bielefeld: Transcript Verlag, 2007. 319 p.

73 JAEGGI, 2013, p. 286.

74 JAEGGI, 2013, p. 287. 